\title{
The problem with inspiration porn: A tentative definition and a provisional critique
}

\begin{abstract}
The term "inspiration porn" is associated with disability advocacy in general and the late activist and comedian Stella Young in particular. It has come into widespread usage over the last few years. I propose the following definition: Inspiration porn is the representation of disability as a desirable but undesired characteristic, usually by showing impairment as a visually or symbolically distinct biophysical deficit in one person, a deficit that can and must be overcome through the display of physical prowess. Inspiration porn superficially appears linked only to medical model / personal tragedy framings of disability, but on closer inspection resonate strongly with the disability movement's advocacy of empowerment and affirmation.
\end{abstract}

Key words: Inspiration porn, representation, affirmation, symbol, deficit, stigma.

\section{Introduction}

The term "inspiration porn" is strongly associated with disability advocacy in general and the late comedian and activist Stella Young in particular. In February 2015, a Google search (anonymously, with no cookies enabled) returned a total of 44,300 results for the exact phrase. By October 2015, the number of results had risen to 66,900. In each case, all of the top ten results were in some way linked to disability. About half were linked to Young's writings and performances, while the rest centered on other prominent disabled people. All twenty results were to some extent critiques of inspiration porn; none endorsed or argued in favor of the phenomenon under discussion.

Since top Google results are generated in accordance with a proprietary algorithm, they form a problematic basis for rigorous analysis. They are, however, a fairly solid indication of cultural salience, and so a suitable jumping-off point for the essayistic explorations I want to conduct here. We, the great and nebulous public we, are talking about inspiration porn, and I am interested both in the prominence of the phenomenon itself, its currently popular label, and the relationship between related, earlier phenomena and labels.

First, a note on usage history. While it is difficult to track the precise origin of the term "inspiration porn", according to Google Trends, it entered general usage in August 2010, though it is difficult to separate pages on which the term appears in the main text from pages on which it appears in paratexts, e.g. advertisements for and links to other texts. Older pages may appear as search results when the search term in fact appears in a more recent, automatically generated sidebar. Effectively, there are not many references prior to Young's 2012 article, "We're not here for your inspiration", published on the Australian Broadcasting Corporation's web site. On these grounds, I will begin this paper by borrowing Young's definition of inspiration porn. If she did not coin the phrase, did much to popularize it and make it stick, and her words make a good starting point:

Inspiration porn is an image of a person with a disability, often a kid, doing something completely ordinary - like playing, or talking, or running, or drawing a picture, or hitting a tennis ball - carrying a caption like "your excuse is invalid" or "before you quit, try". (Young, 2012)

I am going to revisit and adjust this definition shortly. I am also going to depart from Young's usage of "disability", since she is referring to visible impairment, and will try to maintain the disability/impairment distinction more or less along the lines of Thomas (1999). While all of the top images returned by Young's search phrases show people with visible impairment or signs of impairment, such as prosthetic limbs or wheelchairs, not all of these people are doing something 
"completely ordinary". Many of them are performing physically impressive or strenuous activities, or displaying an athletic or bodybuilder's physique. I will therefore revise the definition in order to stress the physicality of the images:

Inspiration porn is a) an image of a person with visible signs of impairment who is b) performing a physical activity, preferably displaying signs of physical prowess, and is c) accompanied by a caption that directs the viewer to be inspired by the image in question.

All parts of the definition are necessary. Throughout human history there are many rich and varied traditions of depicting impairment. The analysis of these traditions and the way in which they represent their subjects is itself a very complex matter. This should not be surprising, given that what we call "impairment" is part of the range of human bodily variation, and that depiction of the human body in its various guises, including every conceivable impairment, is perhaps the overriding concern of visual art and culture (Siebers, 2010). Inspiration porn distinguishes itself partly by a glorifying aesthetic attitude towards its subjects and their physical prowess, partly by its exhortatory attitude towards the viewer.

There are many questions that can be posed about inspiration porn, but the most important one is perhaps: Is it a bad thing or a good thing? Given that inspiration porn exists both as a recognizable phenomenon and a label, answering this question might help us decide how to relate to it. It may seem like I am begging the question here, but this could well be because of the label, not the phenomenon. Is it a priori a bad thing to depict people with impairment succeeding at a task or displaying physical capabilities? Is it a priori a bad thing to depict people with impairment as potential role models, whether for people with similar impairments or for a general audience? Taken separately, both of these questions might very well be answered negatively - as in "no, it is not a bad thing at all"'.

So what was Stella Young arguing against? As I read her, inspiration porn is chiefly problematic because it perpetuates three well-known ideological mechanisms that contribute to misapprehensions about disability and impairment. This isn't to do with the label "inspiration porn", but with the phenomenon to which it refers, namely the depiction of people with impairment in a way that objectifies them, devalues their experiences, and mystifies their place in the world. To wit:

i) Objectification. In inspiration porn, people with impairment are not represented as disabled subjects, but as objects. The audience is implicitly or explicitly assumed not to have impairment, and there is little ground for identification between the two.

ii) Devaluation. The achievements depicted in inspiration porn may be commonplace acts, e.g. walking on prosthetic legs. People with impairment are thus represented as having a smaller scope for achievement than is the case.

iii) Individualization and mystification. Because of its focus on visible impairment and physical prowess, inspiration porn represents disability as a problem located in individual bodies, to be overcome through individual efforts. By constructing disability as an objectively available, visually distinct, individual impairment, inspiration porn obscures structural and systemic causes of disability.

The counterargument could be made - and frequently is made - that positive depictions of people with impairment is a good thing in itself. However, there are by now whole disciplines dedicated to 
the exploration of how ostensibly positive portrayals of marginalized and oppressed groups and individuals contribute to marginalization and oppression; disability studies is only one of these disciplines, and a summary of the literature would take up most of this paper. I will note that Young's arguments, admittedly as I have reconstructed them, draw on classical tropes in disability studies, perhaps particularly the critique of personal tragedy theory and the medical model (Oliver \& Barnes, 2012), and of cultural alienation and the "othering" of impairment and disability (Snyder \& Mitchell, 2006).

These critiques share a central point: the investment of great value in physicality is a problematic aspect of the depiction of people with impairment because it focuses exclusively on individuals while obscuring structures. Sharon Snyder and David Mitchell's work on narrative prosthesis add to this point: they argue that impairment often functions in narratives as an externalized motivating and explanatory device for representing characters. Visible or symbolically signified impairments tend to be used as stand-ins (prostheses) for qualities that cannot easily be visualized, and as totalizing devices of characterization, whereby the impairment totally explains the person. This prosthetic function also extends from individuals to groups, as representations of people with impairment become "potentially allegorical in the sense that the act of characterization encourages readers or viewers to search for a larger concept, experience, or population" (Snyder \& Mitchell, 2000, p. 40). The impairment is the person, and the person is the group.

The totalizing aspect of narrative prosthesis, as Snyder and Mitchell have shown in their analyses of canonical narratives in literature, film, and other cultural forms, means that impairments are construed as limits not only for what a character may achieve, but for what he or she should achieve. This amounts to the devaluation pointed out by Young. Objectification occurs when these limitations are determined by the needs of the overarching narrative or ideology, not with psychologically or biographically integrated aspects of the character that is depicted. Mystification occurs when impairment is portrayed as a necessary and sufficient motivating factor for any course of action, without a need for further explanation. Inspiration porn, then, relies upon an "opportunistic [...] device" (Snyder \& Mitchell, 2000, p. 47) that pervades the history of representation and narrative. It is problematic because the use of such a device has implications for how we understand and construe the lives of both specific individuals and groups of people with impairment.

Fetishizing the extraordinary and defamiliarizing the ordinary: Two kinds of inspiration porn

Why "inspiration porn" rather than a different label? In a TED talk, Stella Young argued that the use of "porn" terminology was appropriate chiefly because of the function of objectification:

I use the term porn deliberately, because they objectify one group of people for the benefit of another group of people. So in this case, we're objectifying disabled people for the benefit of nondisabled people. The purpose of these images is to inspire you, to motivate you, so that we can look at them and think, "Well, however bad my life is, it could be worse. I could be that person." (Young, 2014)

I agree with Young to an extent here, but I think there is a need to distinguish the function of objectification for the purpose of inspiring the audience from the function of inviting comparisons that comfort the audience. The issue may have to do with the distinction between extraordinary and ordinary physical feats. Some images in inspiration porn show people with impairment displaying 
extraordinarily muscular physiques or performing extraordinary feats, other images show them doing ordinary things with their bodies. While I think that both types of images are intimately related with each other as well as with the pornographic gaze, the distinction is important to maintain. In the first case, we are dealing with porn as pure fantasy, in which performers accomplish feats that, desirable though they may be, are unlikely to occur or impossible in real life. In the second case, we are dealing with porn as a different kind of fantasy, in which the viewer is indulging secret fears and experiencing a form of catharsis. Both are porn and both may cause inspiration, but they are not quite the same.

There is no consensus on how to clearly distinguish pornography from other forms of representation on the grounds of content alone (Andrews, 2012), and the problem with defining inspiration porn is ultimately the same as with defining every other type of porn. We may know it when we see it, as in U.S. Supreme Court Justice Potter Stewart's famously pragmatic evasion of the issue, but we cannot easily draw the line without reference both to the intentions of the pornographer and the reactions and preferences of the viewer. One person's footwear is another person's object of fetishism.

However, we are aided by everyday usage, where "porn", when it does not refer to actual porn, has come to signify uncritical aesthetic appreciation of something or other. On the internet forum Reddit, there are sub-forums dedicated to "architecture porn", "food porn", and even "airport porn" ("A place to share and discuss amazing airport features, from beautiful architecture to neat logistics"). When it depicts extraordinary achievement, inspiration porn shares with these phenomena the property of being representational fantasy - whether of overcoming the adversity of impairment, eating a perfect hamburger, or experiencing a well-functioning airport. In this mode, inspiration porn does not invite a thorough consideration of the actual lives of the people being depicted. It presents a single, impressive aspect, and glosses over whatever might disrupt the fantasy.

The other mode of inspiration porn, in which a person with an impairment is doing something rather ordinary, is a different matter. It, too, relies on the notion of a non-disabled audience that knows little about the embodied reality of impairment, and it exploits the mechanisms of narrative prosthesis in order to use people with impairment as psychological funhouse mirrors. An addendum to Young's discussion of objectifying could be: "Well, however bad my life is, it could be worse and yet better. I could be that person and then I would really have a reason to achieve something." The central element in this fantasy is that impairment, notwithstanding all its real-world complications, would actually entail a simpler life. The literature on narrative prosthesis is full of such examples; famously, impairment can be enough to "unquestionably precipitate Ahab's obsessive and vengeful question to kill the white whale" (Snyder \& Mitchell, 2000, p. 120).

\section{Inspirational athletics and the double bind}

Whether it centers on the fantasy of extraordinary achievement or on the fantasy of ordinary achievement for extraordinary reasons, we have noted that inspiration porn tends to focus on a person with a visible impairment or signifier of impairment, typically a wheelchair or a prosthesis, who is performing a physically strenuous activity, and we have noted that the impairment becomes an external symbol of the person's motivation and drive. These foci and mechanisms in inspiration porn mean that it is closely associated with athletics.

Among the most iconic images of inspiration porn is a photograph of the Paralympic athlete Aimee Mullins, who is a double amputee, running on a beach with her carbon-fiber prostheses - famously, 
one of her "12 pairs of legs" (Mullins, 2012). Mullins displays extraordinary achievement. She looks fit and healthy, and is running faster and more gracefully than most people will ever manage. A different iconic image shows a young boy with similar prostheses, wearing a starting number, taking slightly wobbly steps on a running track while wearing a confident smile. He is performing a more ordinary activity, though we are meant to understand that the fact that he is doing it is extraordinary. A third image shows a body builder wearing a red thong and a full-length prosthetic leg with it complicated mechanics and hydraulics exposed to view. A fourth image shows a line of eight body builders, all of them in wheelchairs. The bodybuilders are all flaunting their biceps, triceps, abdominal muscles, and technological accoutrements. They are extraordinary by the very fact of being cyborgs, with all of the benefits and none of the disadvantages of human-machine integration (Howe, 2011; Reeve, 2012).

All of these four images constitute inspiration porn by virtue of having the same caption: WHAT IS YOUR EXCUSE? The question is asked of the audience, and it is an accusation, since all of the people in the image have their manifestly acceptable excuses prominently on display - the World Health Organization's "problem in body function or structure" (WHO, 2001). Other excuses, of course, may not be as visible - uneven strain put on muscles, constant wear on skin, pressure sores, whatever else. We see the results of not availing oneself of these excuses. We see the results of self-denial and exertion of willpower.

These representational frameworks are familiar from the world of elite sports, not least the Paralympic Games. In this arena, the two aspects of inspiration porn - the ordinary and the extraordinary - play off each other in a particularly uncomfortable way, for disabled as well as nondisabled audience. While Paralympic athletes are a select elite, there is an expectation that they will and should serve as credible role models for other people with impairments (Joukowsky \& Rothstein, 2002; Purdue \& Howe, 2012). And while athletes are encouraged to be in peak physical condition, there are strict regimes in place to ensure that they are sufficiently impaired for their category (Peers, $2009,2012)$. Here, the ordinary and the extraordinary form a double bind. The ideal Paralympic athlete is so impaired that ordinary achievement looks inspirational, but not so impaired as to be incapable of truly inspirational, extraordinary accomplishment.

\section{Desirable but undesired: The moral logic of compensatory abilities}

The double bind of inspirational portrayals reflects from Paralympic athletes onto ordinary disabled people. The Paralympic games' ostensible function of "empowering" ordinary disabled people may be utterly illusory, because it promotes an ideal that is beyond the reach of almost everyone (Jackson, Hodges, Molesworth, \& Scullion, 2014).

Equally problematic is the Paralympic Games', and inspiration porn's, implicit logic of moral balance. Inspiration porn does not depict disabled lives simply as being worse than non-disabled lives. Writing more than half a century ago, Erving Goffman, pointed out that disabled people are often viewed to have certain extraordinary characteristics that in some sense compensate for imputed deficits:

We tend to impute a wide range of imperfections on the basis of the original one, and the same time to impute some desirable but undesired [my emphasis] attributes, often of a supernatural cast, such as 'sixth sense', or 'understanding'. (Goffman, 1963, pp. 15-16) 
This observation rings true today; the prevalence of inspiration porn proves the point. "Desirable but undesired" - therein lies the potential for fantasy. A sharp mind compensates for a weak body; blindness implies second sight or special insight. Or as is the case with Paralympic athletes: Impairment begets extraordinary willpower, leading to extraordinary achievement.

The most extreme pop-cultural incarnation of this phenomenon, is the superheroes of Marvel Comics: Radioactive waste giveth (superpowers, a purpose in life), radioactive waste taketh away (sight, social standing, parents). But there are other examples of what might be dubbed "hard-core inspiration porn", in which people with impairments achieve things that are indisputably beyond the ordinary, and where the depiction cares very little for realism. Here we encounter familiar figures that have been described variously as super-crips (or super cripples), cyborgs, and techno-marvels (Barnes, 1992; Norden, 1994). In very different but equally fantastical modes, Robocop, Iron Man, and the Six Million Dollar Man are all demonstrations of the triumph of technology and willpower over physiological damage, much like the John Nash character in A Beautiful Mind demonstrates the triumph of genius over mental illness. Central to the appeal of such characters is the notion of additional or augmented abilities as a compensation for damage. Superheroes and cyborgs are not meant to be taken as realistic depictions of human beings, with or without impairment. (Living subjects of biographical portrayal is a different matter.) But just as inspiration porn such stories adhere to the logic of moral balance, the logic of narrative prosthesis, in which the desirable is inextricably linked with the undesired.

For Paralympic athletes as well as ordinary people, the crucial desirable-but-undesired element is willpower (Barrett, 2014, p. 1577) - which suggests that the inspirational achievements of some people not only reflects positively on the person responsible for the achievement, but reflects negatively on those who but resemble that person fail to achieve the same (Hutcheon \& Lashewicz, 2014; Purdue \& Howe, 2012).

Inspiration porn for the masses: Willpower beyond boundaries

In the realistic mode, a curious instance of inspiration porn centered on willpower played out as a media phenomenon in Norway in 2012 and 2013 (Eide, Grue, \& Vold, 2013). A television program called Ingen grenser (Direct translation: "No borders/limits"), based on the BBC production Beyond Boundaries, became a massive success - the most watched program of the year in 2013, and recipient of numerous awards for the production as well as for its participants. They were physically impaired people who were sent on a wilderness expedition - across Northern Norway in the first season, up a mountain in the second. Most of the participants had visual impairments, hearing impairments, or visually identifiable mobility impairments, and so exemplified the kind of distinctdeficit impairment upon which inspiration porn is contingent. The program was consistently referred to as inspirational in much of the national media coverage - articles describing either the program itself or participants as being inspirational run into triple digits for the years 2012 and 2013, according to search results from a national database for print and digital media (Retriever, 2015).

The Beyond Boundaries concept has been developed and produced in many countries, but the Norwegian case is the most successful to date, as far as I am aware. In a sense, it joins together the two aspects of inspiration porn, that of extraordinary athletic achievement and that of moreordinary achievement. It is practically compulsory for Norwegians to enjoy the outdoors; the national pastime described by word friluftsliv doesn't have a ready English translation, but can be paraphrased as 
"spending time outdoors in a healthy fashion, enjoying the clean air". Still, not even a majority of Norwegians are mountaineers. The tasks set for the participants on Ingen grenser were difficult by most standards, and much of the inspirational effect was derived from seeing them exert themselves. As the introductory voiceover put it:

They have to want more, give more, and cooperate more than everyone thinks possible. [...] Together they will show that nothing can prevent them from carrying out a grueling expedition. Together they will show that abilities and optimism have ... no limits. (Mastiff AS, 2013)

Criticism against Ingen grenser from disability activists was extensive, but did not effectively resonate in the public sphere. The criticism was made largely on two grounds - that the program created unrealistic expectations for disabled people, and that it constituted a freak show because of its display of bodies with impairments (Grue, 2014). The latter accusation quickly became a doubleedged sword, with the critics placed in the role of prejudiced observer - they were the only ones who saw disabled people as freaks. The accusations about unrealistic expectations, as is also the case with many debates about the Paralympic games, were met in two ways: By pointing out that this was entertainment, and by stressing the inspirational and aspirational functions of Ingen grenser.

It appears likely that the phenomenon referred to in this paper as inspiration porn is deeply enmeshed with mainstream cultural attitudes to disability and impairment, attitudes that are prevalent historically as well as in the present moment. Young's label "inspiration porn" gives us a way to encapsulate and further explore the complicated relationship between the unmarked observer and the observed person with an impairment, a relationship that is built on desires of the undesirable and fantasies of transcendence.

The mechanics of inspiration porn show us that "pure" fantasies, e.g. of simply being stronger, faster, and richer than one actually is, are not necessarily more appealing than impure fantasies. Pure fantasies lack dynamism, excitement, and dramatic potential. Visibly manifest impairment provides a point of entry and a focal point for a different kind fantasy - and a rich potential for projection. Tobin Siebers, in his critique of the psychoanalytic tradition, pointed out that disability is often portrayed as an excuse for unbridled narcissism:

\footnotetext{
We grow anxious because life is full of uncertainties, and we blame ourselves for our failure to adjust, but we blame ourselves for a thousand and one reasons. The inability to manage many reasons is neurosis. People with disabilities, according to this theory, have one good reason for all their failures - the tender organ - and so the radical uncertainty of human existence disappears or at least becomes more manageable. (Siebers, 2008, p. 39)
}

In reality, disabled life, life with an impairment, tends to be less rather than more manageable. As a fantastical projection, however, the view presented by Siebers holds a persistent appeal. Not coincidentally, the richer a person is, the likelier that person is to agree that "poor people have it easy" (Pew Research Center, 2015, p. 8) - as opposed to having the extremely difficult problem of not having enough money. Much like actual porn, inspiration porn is single-tracked, and focuses the mind to an impressive degree. For that, it requires a prosthetic point of fixation - a visual expression of the desirable but undesired.

\section{Inspiration or empowerment? An uncomfortable analogy}

The label "inspiration porn" adds to the repertoire of disability studies critique. Giving something a name provides a way to recognize it more easily. This paper has summed up some of the reasons 
why the phenomenon is problematic: It ignores disability's status as a predicament (Shakespeare, 2013), glosses over complex embodiment (Siebers, 2008), and precludes understanding of the interactions between disability, impairment, and chronic illness (Thomas, 1999; Wendell, 1996, 2013). Still, the critique must me expanded. Inspiration porn has more than a foothold in central discourses of disability. It appeals to enduring stereotypes by featuring much overcoming of obstacles in the form of physical challenges. It is easily recognizable as a form of medicalization (Conrad, 2008; I. K. Zola, 1977; I. Zola, 1972) and draws on constructions of disability as a personal tragedy (Oliver \& Barnes, 2012; Oliver, 1990) that lacks a socio-political or structural dimension. The deficit in structural analysis is often noted by people who are familiar with inspiration porn, including one of the most depicted people of the genre, Aimee Mullins. Mullins notes in her TED talk that even her high-tech, marvelous "12 pairs of legs" are a product of complex institutional dynamics and a privilege of resources and wealth. Inspiration porn is, on one level, as transparently unrealistic as other forms of porn.

Perhaps less obviously, a comprehensive critique of inspiration porn must also encompass discourses of empowerment and affirmation that are integral to the disability movement and to parts of disability studies. The problem,put as simply as possible, is that it is difficult to find something good about being disabled. Sometimes, attempts to do so leads to problematic places. John Swain and Sally French have proposed an affirmative model of disability which depends on the assertion of positive identity:

\footnotetext{
An affirmative model is being generated by disabled people through a rejection of the tragedy model, within which their experiences are denied, distorted or re-interpreted, and through building on the social model, within which disability has been redefined. The affirmative model directly challenges presumptions of personal tragedy and the determination of identity through the value-laden presumptions of non-disabled people. [...] Embracing an affirmative model, disabled individuals assert a positive identity, not only in being disabled, but also in being impaired. In affirming a positive identity of being impaired, disabled people are actively repudiating the dominant value of normality. (Swain \& French, 2000, p. 578)
}

The trouble with this definition is that it is very difficult to articulate what "a positive identity" should be. Particularly if it is going to be linked to impairment itself, not only to the kind of solidarity, community, and fellowship that characterizes the disability movement and many other social movements, then the affirmative model encounters a dilemma: The negative valuation of impairment.

To reverse this valuation entails a fairly drastic semantic operation, which often produces infelicities like "differently abled", and undermines the basis for political action, economic redistribution, and social justice. If one is to maintain the valuation, however, one must then find some way of compensating the negative with something positive. And this is how inspiration porn stars are born: As creatures of compensatory achievement.

In practice, positive portrayals of disabled people, i.e. people with impairment, are easiest to frame in terms of physical achievement. Physical achievement can be visualized more easily than other kinds of achievement. Activists, advocates, and NGOs know this. It is why they routinely publish images of disabled people displaying physical prowess. The rhetorical technique extends to logos: The American grassroots organization ADAPT has as its logo a wheelchair user ripping chains in half, as does the Norwegian independent living cooperative ULOba. Such representations of physically strong disabled people are clearly metaphors for the breaking of institutional barriers. Nevertheless, 
physical strength is the symbolic domain in which the metaphor is anchored, and this implies a degree of acceptance of physical strength as a positive factor (Lakoff \& Johnson, 1980; Lakoff \& Turner, 1989).

Inspiration porn focuses on impairment, and specifies disability as biophysically caused and symbolically distinct. This is at least partly in keeping with medical model thought. However, the fantasy that disability is a single, isolated, easily conceptualized entity - one that can be completely compensated for - haunts the history of disability studies in many forms. Whether in the parable of Vic Finkelstein's village adapted entirely for wheelchair users (Finkelstein, 1988) or in the Nordic relational model's construal of disability as a "gap" that can ultimately be closed (Tøssebro, 2004), disability studies has given rise to many utopian scenarios in which disability is either eliminated or made irrelevant. Although inspiration porn is a particularly problematic outgrowth of the utopian tendency, it feeds off the same soil.

The rhetoric of empowerment and inspiration porn tell variants of the same simple story: Disabled people are capable of anything. That is obviously false. Disabled people are no more capable of "anything" than non-disabled people are; they are limited by their bodies and the world in which they live, just like everyone else. Humans have different capabilities, both within and outside what we have termed, at least since the mid- $19^{\text {th }}$ century, the "normal range" (Davis, 1997). If we acknowledge that non-disabled people are capable of varying degrees of achievement, then we should probably acknowledge that this holds true of disabled people as well.

I will end this short paper by proposing a revised definition of inspiration porn:

Inspiration porn is the representation of disability as a desirable but undesired characteristic, usually by showing impairment as a visually or symbolically distinct biophysical deficit in one person, a deficit that can and must be overcome through the display of physical prowess.

This definition is meant to be temporary, and I sincerely hope that it will soon be improved upon. In the meantime, it is intended for two purposes: First, I want to stress the fact that inspiration porn exists, and that its premises is something that disability activists and disability scholars should be wary of in their own rhetoric as well as that of others. Second, I want to highlight the persistence, and persistently problematic impulse towards isolating disability-as-impairment in visual, symbolical, and conceptual ways.

The phrase "visually or symbolically distinct" is crucial, not least because it is so closely linked to the notion of the desirable but undesired. It explains why some kinds of impairment - the kind that is easily signified - are so prominent in inspiration porn. We know that some illnesses and impairments are more prestigious than others (Album \& Westin, 2008; Grue, Johannessen, \& Rasmussen, 2015), and that attention is often drawn to illnesses and impairments that have an association with medical intervention, or technology, or are easily recognized as belonging to a distinct body part. These mechanisms obscures complex embodiment, and makes people with hidden impairments and chronic illnesses even more marginalized than they already are.

We are very likely, at least according to the Google Ngram viewer, talking more about disability using that particular word - than at any time in history. That does not mean that we are talking about disability in a way that makes it relevant for more people than every before. Inspiration porn 
shares with some forms of empowerment rhetoric the symbolic function of constructing disability as a desirable but undesired characteristic of individuals. It is the shared connection as well as the symbolic function that makes it deserving of critique.

\section{References}

Album, D., \& Westin, S. (2008). Do diseases have a prestige hierarchy? A survey among physicians and medical students. Social Science \& Medicine, 66(1), 182-188. doi:10.1016/j.socscimed.2007.07.003

Andrews, D. (2012). Toward A More Valid Definition of "Pornography." The Journal of Popular Culture, 45(3), 457-477. doi:10.1111/j.1540-5931.2012.00939.x

Barnes. (1992). Disabling imagery and the media An exploration of the principles for media representations of disabled people. Lo: British Council of Organisations of Disabled People.

Barrett, T. (2014). De-individualising autobiography: a reconsideration of the role of autobiographical life writing within disability studies. Disability \& Society, 29(10), 1569-1582.

doi:10.1080/09687599.2014.958435

Conrad, P. (2008). The Medicalization of Society: On the Transformation of Human Conditions into Treatable Disorders. JHU Press.

Davis, L. J. (1997). Nude Venuses, Medusa's body, and phantom limbs: Disability and visuality. In S. L. Snyder \& D. T. Mitchell (Eds.), The body and physical difference: Discourses of disability (pp. 5170). Ann Arbor: University of Michigan Press.

Eide, E., Grue, J., \& Vold, T. (2013). Stort felt - liten dekning. Medierepresentasjoner av mennesker med nedsatt funksjonsevne [Big field - little coverage. Media representations of disabled people]. Oslo: Høgskolen i Oslo og Akershus.

Finkelstein, V. (1988). To Deny or Not to Deny Disability - What is disability? Physiotherapy, 74(12), 650-651.

Goffman, E. (1963). Stigma: Notes on the Management of Spoiled Identity. Harmondsworth: Penguin.

Grue. (2014). Ideologiske premisser for Ingen grenser [Ideological preconditions for Beyond Boundaries]. In E. Eide, J. Grue, \& T. Vold (Eds.), Ut av medieskyggen [Out from the media shadow] (pp. 68-80). Oslo: Fagbokforlaget.

Grue, J., Johannessen, L. E. F., \& Rasmussen, E. F. (2015). Prestige rankings of chronic diseases and disabilities. A survey among professionals in the disability field. Social Science \& Medicine, 124(1), 180-186. doi:10.1016/j.socscimed.2014.11.044

Howe, P. D. (2011). Cyborg and supercrip: the Paralympics technology and the (dis) empowerment of disabled athletes. Sociology, 45(5), 868-882.

Hutcheon, E., \& Lashewicz, B. (2014). Theorizing resilience: critiquing and unbounding a marginalizing concept. Disability \& Society, 29(9), 1383-1397. doi:10.1080/09687599.2014.934954 
Jackson, D., Hodges, C. E. M., Molesworth, M., \& Scullion, R. (2014). Reframing Disability? Media, (Dis)Empowerment, and Voice in the 2012 Paralympics. London: Routledge.

Joukowsky, A. A. W., \& Rothstein, L. (2002). Raising the bar: new horizons in disability sport. New York: Umbrage Editions.

Lakoff, G., \& Johnson, M. (1980). Metaphors We Live By. Chicago: University of Chicago Press.

Lakoff, G., \& Turner, M. (1989). More Than Cool Reason: A Field Guide to Poetic Metaphor. Chicago: University of Chicago Press.

Mastiff AS. (2013). Ingen grenser. Norway. Retrieved from http://www.mastiff.no/portfolio/ingengrenser/

Mullins, A. (2012). My 12 pairs of legs. TED. Retrieved February 11, 2015, from http://www.ted.com/talks/aimee_mullins_prosthetic_aesthetics?language=en

Norden, M. F. (1994). The cinema of isolation: A history of disability in the movies. New Jersey: Rutgers University Press.

Oliver, M. (1990). The Politics of Disablement. Critical Texts in Social Work and the Welfare State. London: MacMillan Press.

Oliver, M., \& Barnes, C. (2012). The new politics of disablement. Palgrave Macmillan.

Peers, D. (2009). (Dis) empowering Paralympic histories: absent athletes and disabling discourses. Disability \& Society, 24(5), 653-665.

Peers, D. (2012). Interrogating disability: the (de) composition of a recovering Paralympian. Qualitative Research in Sport, Exercise and Health, 4(2), 175-188.

Pew Research Center. (2015). The Politics of Financial Insecurity: A Democratic Tilt, Undercut by Low Participation. Retrieved from http://www.people-press.org/files/2015/01/1-8-15-Financialsecurity-release.pdf

Purdue, D. E. J., \& Howe, P. D. (2012). Empower, inspire, achieve:(dis) empowerment and the Paralympic Games. Disability \& Society, 27(7), 903-916.

Reeve, D. (2012). Cyborgs, Cripples and iCrip: Reflections on the Contribution of Haraway to Disability Studies. In Disability and Social Theory: New Developments and Directions (p. 12).

Retriever. (2015). Retriever Media Archive. Retriever Norge AS. Retrieved from http://www.retriever-info.com/atekst.php

Shakespeare, T. (2013). Disability Rights and Wrongs Revisited. London: Routledge.

Siebers, T. (2008). Disability theory. Corporealities. Ann Arbor: University of Michigan Press.

Siebers, T. (2010). Disability aesthetics. Ann Arbor: University of Michigan Press.

Snyder, S. L., \& Mitchell, D. T. (2000). Narrative prosthesis : disability and the dependencies of discourse. Corporealities. Ann Arbor; [Great Britain]: University of Michigan Press.

Snyder, S. L., \& Mitchell, D. T. (2006). Cultural locations of disability. Chicago: University of Chicago 
Press.

Swain, J., \& French, S. (2000). Towards an affirmation model of disability. Disability \& Society, 15(4), 569-582.

Thomas, C. (1999). Female forms : experiencing and understanding disability. Disability, human rights and society. Buckingham: Open University Press.

Tøssebro, J. (2004). Understanding Disability. Scandinavian Journal of Disability Research, 6(1), 3-7.

Wendell, S. (1996). The rejected body : feminist philosophical reflections on disability. New York: Routledge.

Wendell, S. (2013). Unhealthy Disabled: Treating Chronic Illnesses as Disabilities. In L. J. Davis (Ed.), The Disabilit Studies Reader (4th ed.) (pp. 161-173). New York: Routledge.

WHO. (2001). International classification of functioning, disability and health: ICF. Geneva: World Health Organization.

Young, S. (2012). We're not here for your inspiration. ABC. Retrieved from http://www.abc.net.au/news/2012-07-03/young-inspiration-porn/4107006

Young, S. (2014). I'm not your inspiration, thank you very much. TED. Retrieved February 10, 2015, from

http://www.ted.com/talks/stella_young_i_m_not_your_inspiration_thank_you_very_much?lan guage $=e n$

Zola, I. (1972). Medicine as an institution of social control. The Sociological Review, 20(4), 487-504.

Zola, I. K. (1977). Healthism and disabling medicalization. In I. Illich (Ed.), Disabling professions (pp. 41-67). London: Marion Boyars. 